\title{
Eicosenoic Acid
}

National Cancer Institute

\section{Source}

National Cancer Institute. Eicosenoic Acid. NCI Thesaurus. Code C68361.

A monounsaturated long-chain fatty acid with a 20-carbon backbone and the sole double bond originating from the 5th, 6th, 7th, 9th, 11th 12th or 15th positions from the methyl end. 